\title{
DIREITOS HUMANOS: A AGENDA QUE COMEÇA EM 2016 ENTREVISTA COM A PROFA. DRA. FLÁVIA PIOVESAN, PPGD | PUC-SP
}

A EJJL reativa a seção de entrevistas para oferecer ao seu público leitor este diálogo, de natureza experimental, entre uma pesquisadora notável no campo dos direitos fundamentais, direitos humanos e direitos constitucionais (entrevistada) e pesquisadores da Rede Brasileira de Pesquisa em Direitos Fundamentais. Nesta nossa entrevista, seis Programas de Pós-Graduação stricto sensu (mestrados e doutorados), todos com área de concentração ou linha de pesquisa em Direitos Humanos e Direitos Fundamentais, aceitaram o convite da EJJL.

Flávia Piovesan é uma das mais destacadas pesquisadoras e autoras do Brasil, no tema dos direitos humanos. É doutora em Direito pela Pontifícia Universidade Católica de São Paulo (1996). É professora de Graduação e Pós-Graduação em Direito dessa mesma Universidade paulista. Foi Visiting fellow do Human Rights Program da Harvard Law School (1995 e 2000); visiting fellow do Centre for Brazilian Studies da University of Oxford (2005); visiting fellow do Max-Planck-Institute for Comparative Public Law and International Law (Heidelberg, 2007 e 2008) e Humboldt Foundation Georg Forster Research Fellow no Max-Planck-Institute for Comparative Public Law and International Law (2009-2011). É membro do Conselho de Defesa dos Direitos da Pessoa Humana; membro da UN High Level Task Force on the implementation of the right to development; e membro do OAS Working Group para o monitoramento do Protocolo de San Salvador em matéria de direitos econômicos, sociais e culturais.

Dentre suas publicações mais recentes, destacam-se:

Livros:

PIOVESAN, F. Direitos Humanos e o Direito Constitucional Internacional. 15. ed. São Paulo: Saraiva, 2015. v. 15. 711p.

PIOVESAN, F. Direitos Humanos e Justiça Internacional: Estudo Comparativo dos Sistemas Interamericano, Europeu e Africano. 6. ed. São Paulo: Saraiva, 2015. v. 6. 392p. PIOVESAN, F. Temas de Direitos Humanos. 8. ed. São Paulo: Saraiva, 2015. v. 8. 632p.

PIOVESAN, F.; FACHIN, M. G. (Org.). Direitos Humanos na ordem contemporânea: proteção nacional, regional e global. Curitiba: Juruá, 2015. v. 6. 492p.

Artigos:

PAMPLONA, D. A.; PIOVESAN, F. O Instituto do Refugio no Brasil: Práticas Recentes. Revista Direitos Fundamentais \& Democracia (UniBrasil), v. 17, p. 43- 
55, 2015 e Direitos humanos e o constitucionalismo regional transformador. Revista dos Tribunais (São Paulo. Impresso), v. 952, p. 141-166, 2015.

Esta entrevista foi organizada por Carlos Luiz Strapazzon e Andrea A. Costa e planejada para compor esta edição especial sobre a Agenda 2015-2030 para o desenvolvimento humano e também sobre situações de graves violações a esses direitos.

Entrevistadores

Carlos Luiz Strapazzon e Robison Tramontina, Unoesc, Chapecó, SC

Gina Vidal Marcilio Pompeu, Fortaleza, Ceará

Ingo Wolfgang Sarlet, PUC-RS, Porto Alegre, RS.

Margareth Leister, Unifieo

Monia Clarissa Henning, Unisc, Santa Cruz do Sul, RS

Rosalice Fidalgo Pinheiro e Eduardo Biacchi Gomes, Unibrasil, Curitiba, PR

\section{Editores da entrevista}

Carlos Luiz Strapazzon, Editor-Chefe EJJL

Robison Tramontina, Editor Assistente EJJL

Andrea A. Costa, Doutoranda PUC-PR, Curitiba, PR

\section{PPGD PUC-RS/Editores da EJJL | A seu ver, o diálogo entre Cortes em} matéria de direitos humanos e o diálogo entre direitos humanos estabelecidos em tratados internacionais e direitos fundamentais constitucionais têm sido produtivo no Brasil? O Brasil ainda precisa aprimorar muito esse diálogo?

Direitos humanos e diálogo entre jurisdições constitui tema de especial relevância e complexidade para a cultura jurídica contemporânea, refletindo a emergência de um novo paradigma.

Testemunhamos os delineamentos de um novo paradigma a nortear a cultura jurídica latino-americana na atualidade, no qual aos parâmetros constitucionais somam-se os parâmetros convencionais, na composição de um trapézio aberto ao diálogo, aos empréstimos e à interdisciplinariedade, a ressignificar o fenômeno jurídico sob a inspiração do human rights approach.

É sob a perspectiva desta transição paradigmática - marcada pela crise do paradigma tradicional e pela emergência de um novo paradigma jurídico - que ganha crescente realce a análise dos direitos humanos e do diálogo entre jurisdições, abrangendo o diálogo regional-regional; regional-nacional; e nacional-nacional, com destaque, sobretudo, ao controle da convencionalidade exercido pela Corte Interamericana.

No que se refere especificamente ao diálogo horizontal de jurisdições no âmbito latino-americano, este ainda se mostra incipiente. Por vezes - como revela o caso brasileiro - as alusões ao Direito Comparado e aos seus precedentes tem como foco preferencial a jurisprudência europeia e norte-americana (e não a latino-ame- 
ricana). Levantamento realizado em 2009 acerca das decisões do Supremo Tribunal Federal do Brasil baseadas em precedentes judiciais de órgãos internacionais e estrangeiros aponta que 80 casos aludem à jurisprudência da Suprema Corte dos EUA, ao passo que 58 casos aludem à jurisprudência do Tribunal Constitucional Federal da Alemanha - enquanto que apenas 2 casos remetem à jurisprudência da Corte Interamericana ${ }^{1}$.

Incipiente ainda é a jurisprudência do Supremo Tribunal Federal que realiza o controle de convencionalidade (à luz do diálogo com o sistema interamericano, seus parâmetros protetivos e sua jurisprudência). Também incipiente é o diálogo horizontal do Supremo com outras jurisdições latino-americanas.

Nesse sentido, considerando que a região compartilha dos mesmos desafios em relação à consolidação democrática, baixa densidade do Estado de Direito e precária tradição de respeito dos direitos humanos, essencial mostra-se avançar e fortalecer o diálogo horizontal entre jurisdições latino-americanas ${ }^{2}$. Um caso exemplar refere-se à extraordinária jurisprudência em matéria de direitos sociais fomentada pela Corte Constitucional da Colômbia, que em muito poderia contribuir com a maior proteção judicial destes direitos na região.

\section{PPGD Unisc-RS/Editores da EJJL | A Corte Interamericana de Direi-} tos Humanos tem realizado um trabalho interessante em termos de ampliação de sua atuação, desenvolvendo conceitos como o controle de convencionalidade e a extensão da aplicação dos fundamentos de suas decisões a todos os países que se sujeitam à sua jurisdição. Além disso, ela também tem adotado, cada vez mais, uma postura prospectiva, assentada em uma noção de dimensão objetiva dos direitos contidos na Convenção, no sentido de, mais do que simples reparações, valer-se de sentenças estruturantes, voltadas a uma concepção preventiva de violações de direitos humanos. Parece necessário, a essa altura, uma especial atenção à organização operacional e burocrática para assegurar o cumprimento dessas decisões e à criação das políticas públicas destinadas à sua consecução. Qual é a sua avaliação sobre a institucionalização desses procedimentos no Brasil e que estratégias poderiam ser adotadas para que haja uma maior efetividade e celeridade na incorporação dessas determinações da Corte Interamericana?

O sistema interamericano invoca um parâmetro de ação para os Estados, legitimando o encaminhamento de comunicações de indivíduos e entidades não governamentais se esses standards internacionais são desrespeitados. Além da fixação/

\footnotetext{
1 Ver SILVA, Virgilio Afonso da. Integração e Diálogo Constitucional na América do Sul. In: BOGDANDY, Armin Von; PIOVESAN, Flavia; ANTONIAZZI Mariela Morales (Coord.). Direitos Humanos, Democracia e Integração Jurídica na América do Sul. Rio de Janeiro: Lúmen Júris, 2010. p. 530.

2 Como analisa Virgilio Afonso da Silva: "a jurisprudência do Supremo Tribunal Federal (do Brasil) é altamente permeável a argumentos utilizados em alguns Tribunais de outros países, mas ignora por completo a jurisprudência dos Tribunais vizinhos." (Ver: SILVA, 2010, p. 530).
} 
difusão de standards protetivos em matéria de direitos humanos, o sistema interamericano permite compensar déficits internos, fomentando uma nova dinâmica de poder entre os atores sociais.

No período de 1970 a 2014, 138 casos contra o Estado brasileiro foram admitidos pela Comissão Interamericana. À luz dos 138 casos levantados, optou-se por criar uma tipologia de análise, orientada pela natureza do direito violado. Nesse sentido, foram criadas dez categorias, que correspondem a casos de: 1) detenção arbitrária, tortura e assassinato cometidos durante o regime autoritário militar; 2) violação dos direitos dos povos indígenas; 3) violência rural; 4) violência policial e outras violações praticadas por agentes estatais; 5) violação dos direitos de crianças e adolescentes; 6) violação dos direitos das mulheres; 7) discriminação racial; 8) violência contra defensores de direitos humanos; 9) violação de direitos de outros grupos vulneráveis; e 10) violação a direitos sociais.

Quanto ao impacto da litigância internacional no âmbito brasileiro, destaca-se que casos submetidos à Comissão Interamericana têm apresentado relevante impacto no que se refere à mudança de legislação e de políticas públicas de direitos humanos, propiciando significativos avanços internos. A título ilustrativo, cabe menção a 6 avanços: a) os casos de violência policial, especialmente os que denunciam a impunidade de crimes praticados por policiais militares, foram fundamentais para a adoção da Lei n. 9.299/96, que determinou a transferência da Justiça Militar para a Justiça Comum do julgamento de crimes dolosos contra a vida cometidos por policiais militares; b) o Caso 12263, relativo ao assassinato de estudante por deputado estadual, foi essencial para a adoção da Emenda Constitucional n. 35/2001, que restringe o alcance da imunidade parlamentar no Brasil; c) o Caso 12378, envolvendo denúncia de discriminação contra mães adotivas e seus respectivos filhos, em face de decisão definitiva proferida pelo Supremo Tribunal Federal, que negou direito à licença-gestante à mãe adotiva, foi também fundamental para a aprovação da Lei n. 10.421/2002, que estendeu o direito à licença-maternidade às mães de filhos adotivos; d) o Caso 12051 (Caso Maria da Penha Maia Fernandes), que resultou na condenação do Brasil por violência doméstica sofrida pela vítima, culminou na adoção da Lei n. 11.340/2006 ("Lei Maria da Penha"), que cria mecanismos para coibir a violência doméstica e familiar contra a mulher'; e) os casos envolvendo violência contra defensores de direitos humanos contribuíram para a adoção do Programa Nacional de Proteção aos Defensores de Direitos Humanos; e f) os casos envolvendo violência rural e trabalho escravo contribuíram para a adoção do Programa Nacional para a Erradicação do Trabalho Escravo.

\footnotetext{
3 O projeto de lei foi fruto do trabalho do Grupo Interministerial criado pelo Decreto n. 5.030, de 31.3.2004. Note-se que, na exposição de motivos do aludido projeto de lei, referência expressa é feita ao Caso Maria da Penha, em especial às recomendações formuladas pela Comissão Interamericana.
} 
Pode-se concluir que o sistema interamericano de proteção dos direitos humanos oferece importantes estratégias de ação, potencialmente capazes de contribuir para o reforço da promoção dos direitos humanos no Brasil.

Quanto à Corte Interamericana, tendo em vista que o Estado brasileiro apenas reconheceu sua competência jurisdicional em dezembro de 1998 e considerando que somente Estados e a Comissão Interamericana podem acessá-la (após esgotados os procedimentos perante a Comissão Interamericana, nos termos dos arts. 48 a 50 da Convenção Americana), verifica-se até o presente momento um número reduzido de casos. Com efeito, até julho de 2015, apenas 11 casos haviam sido encaminhados à Corte Interamericana contra o Estado brasileiro. Deste universo, 7 são casos contenciosos e 4 envolvem medidas provisórias ${ }^{4}$.

A respeito do cumprimento de sentenças da Corte pelo Estado Brasileiro, observa-se que o Brasil em geral tem cumprido a parte da sentença concernente ao pagamento de indenização pecuniária e à publicação da decisão em imprensa de ampla circulação nacional. O desafio atém-se ao cumprimento da sentença quando há a determinação de obrigação de fazer, notadamente no que se refere ao combate à impunidade (dever do Estado de processar e punir o violador). Na resposta à terceira questão, serão identificadas propostas visando ao fortalecimento e ao aprimoramento da implementação das sentenças da Corte no caso brasileiro.

\section{PPGD Unibrasil-PR/Editores da EJJL. Comparando-se o Brasil com países, como o México, Argentina, Chile e Colômbia, como você analisa o posicio- namento do STF em relação ao cumprimento das decisóes da Corte Interamerica- na? No que, precisamente, é preciso evoluir?}

\footnotetext{
4 No que se refere aos 7 casos contenciosos, destacam-se: a) caso Gilson Nogueira de Carvalho, referente à denúncia de assassinato de defensor de direitos humanos por grupo de extermínio no Rio Grande do Norte, encaminhado pela Comissão Interamericana à Corte em 19 de janeiro de 2005 (Caso 12058); b) caso Damião Ximenes Lopes, referente à denúncia de morte por espancamento em clínica psiquiátrica no Ceará, encaminhado pela Comissão Interamericana à Corte em 13 de outubro de 2004 (Caso 12237); c) caso Escher e outros, referente à denúncia de interceptações telefônicas de integrantes do MST; d) caso Garibaldi, referente à denúncia de execução sumária; e) caso Gomes Lund, referente ao desaparecimento de pessoas na guerrilha do Araguaia e à incompatibilidade da lei de anistia brasileira com a Convenção Americana de Direitos Humanos; e) o caso Cosme Rosa Genoveva, Evandro de Oliveira e outros (Favela Nova Brasília), referente à denúncia de execução extrajudicial de 26 pessoas, inclusive 6 adolescentes, no marco de atuação policial da Polícia Civil do Rio de Janeiro de 18 de outubro de 1994 a 8 de maio de 1995 na Favela Nova Brasília, submetido em 19 de maio de 2015; e f) o caso dos Trabalhadores da Fazenda Brasil Verde, referente a trabalho escravo, submetido em 6 de março de 2015. Quanto aos 4 casos envolvendo medidas provisórias, destacam-se: a) caso Presídio Urso Branco, referente à denúncia de morte e maus-tratos de detentos no presídio de Rondônia, no qual, em virtude da extrema gravidade e urgência e para evitar dano irreparável à vítima (ver art. 74 do Regulamento da Comissão Interamericana), a Corte decidiu ordenar medidas provisórias de proteção de detentos do referido presídio; b) caso dos adolescentes privados de liberdade no "Complexo do Tatuapé" da FEBEM, em que a Corte ordenou medidas provisórias para determinar ao Estado brasileiro que adotasse de forma imediata as medidas necessárias para proteger a vida e a integridade pessoal dos adolescentes internos no "Complexo do Tatuapé" da FEBEM, assim como a de todas as pessoas que se encontrem em seu interior; c) caso da Penitenciária "Dr. Sebastião Martins Silveira", em Araraquara, em que a Corte ordenou ao Estado que adotasse de forma imediata as medidas necessárias para proteger a vida e a integridade de todas as pessoas privadas de liberdade na Penitenciária de Araraquara, bem como das pessoas que possam ingressar no futuro, na qualidade de detentos; e d) caso da Unidade de Internação Socioeducativa, em Cariacica, no Espírito Santo. Ver Resolução da Corte de 25 de fevereiro de 2001, disponível em: < http://www.corteidh.or.cr/docs/medidas/socioeducativa_Se_01_portugues.pdf>.
} 
É fundamental assegurar o cabal e pleno cumprimento às sentenças da Corte Interamericana por parte do Estado Brasileiro, no marco de seus três poderes na esfera federativa. Na experiência argentina, a Corte Suprema reconhece a importância de incorporar os parâmetros protetivos convencionais e a jurisprudência da Corte Interamericana, realizando de forma efetiva o controle de convencionalidade.

Como sustenta Antonio Augusto Cançado Trindade: "O futuro do sistema internacional de proteção dos direitos humanos está condicionado aos mecanismos nacionais de implementação." 5

Para tanto, são lançados 7 desafios:

1) Fortalecer o diálogo entre o sistema interamericano e o Estado Brasileiro conferindo eficácia jurídica direta, imediata e obrigatória às decisões internacionais;

2) Endossar a responsabilidade internacional do Estado em matéria de direitos humanos (emergencial é densificar o princípio da boa-fé no âmbito internacional por parte dos Poderes Executivo, Legislativo e Judiciário, em todas as esferas federativas);

3) Fortalecer o controle de convencionalidade mediante a incorporação dos parâmetros interamericanos convencionais e jurisprudenciais pelo Estado Brasileiro;

4) Fomentar uma cultura jurídica inspirada em novos paradigmas jurídicos e na emergência de um novo Direito Público marcado pela estatalidade aberta, diálogo jurisdicional e prevalência da dignidade humana em um sistema multínivel;

5) Fortalecer o sistema interamericano de proteção de direitos humanos: universalidade, institucionalidade, independência, sustentabilidade e efetividade;

6) Avançar no diálogo do sistema interamericano com a sociedade civil; e

7) Avançar na proteção dos direitos humanos, da democracia e do Estado de Direito na região

Finalmente, considerando o contexto latino-americano marcado por acentuada desigualdade social e violência sistêmica, fundamental é avançar na afirmação dos direitos humanos, da democracia e do Estado de Direito na região.

O sistema interamericano rompe com o paradoxo de sua origem. Nascido em um contexto regional marcado por regimes ditatoriais - seguramente com a expectativa de reduzido impacto por parte dos então Estados autoritários - o sistema se consolida e se fortalece como ator regional democratizante, provocado por com-

\footnotetext{
5 Ver: TRINDADE, Antônio Augusto Cançado; ROBLES, Manuel E. Ventura, El Futuro de la Corte Interamericana de Derechos humanos. 2. ed. rev. e atual. San José/Costa Rica: Corte Interamericana de Direitos Humanos e UNHCR, 2004. p. 91.
} 
petentes estratégias de litigância da sociedade civil em um transnational network a lhe conferir elevada carga de legitimação social.

O sistema interamericano permitiu a desestabilização dos regimes ditatoriais; exigiu justiça e o fim da impunidade nas transições democráticas; e agora demanda o fortalecimento das instituições democráticas com o necessário combate às violações de direitos humanos e proteção aos grupos mais vulneráveis. O sistema interamericano tem assim concretizado o potencial emancipatório dos direitos humanos.

4. PPGD Unifieo-SP/Editores da EJJL. Em 24 de novembro de 2010, o Brasil foi condenado, por unanimidade, pela Corte Interamericana de Direitos Humanos (CorteIDH) em razão de crimes cometidos pelo Estado brasileiro na chamada Guerrilha do Araguaia, no Caso Gomes Lund e outros v. Brasil. Para aquela Corte, as disposiçóes da Lei da Anistia brasileira que impedem a investigação e a sanção a graves violações de direitos humanos são incompatíveis com a Convenção Americana e não podem permanecer como obstáculo para a investigação dos fatos, nem para a identificação e punição dos responsáveis. No Brasil há vários inquéritos em andamento e também há processos judiciais envolvendo episódios de violência, morte, desaparecimentos, durante os anos 60 e 70 . Em sua opinião, há possibilidade concreta de os Tribunais superiores reverterem a decisão em Habeas Corpus do TRF1, que trancou a ação penal em face do Major Sebastiáo Curió Rodrigues de Moura, pelos motivos de prescrição e de incidência da lei de Anistia?

A resposta é afirmativa. Entendo que há possibilidade concreta de os Tribunais superiores reverterem a decisão em Habeas Corpus do TRF1, que trancou a ação penal em face do Major Sebastião Curió Rodrigues de Moura, pelos motivos de prescrição e de incidência da lei de Anistia, à luz da sentença da Corte Interamericana no caso Gomes Lund.

Com efeito, no caso Gomes Lund, em sentença proferida em 24 de novembro de 2010, a Corte Interamericana condenou o Brasil em virtude do desaparecimento de integrantes da guerrilha do Araguaia durante as operações militares ocorridas na década de 1970. O caso foi submetido à Corte pela Comissão Interamericana, ao reconhecer que o caso "representava uma oportunidade importante para consolidar a jurisprudência interamericana sobre leis de anistia em relação aos desaparecimentos forçados e às execuções extrajudiciais, com a consequente obrigação dos Estados de assegurar o conhecimento da verdade, bem como de investigar, processar e punir graves violações de direitos humanos." Em sua histórica sentença, a Corte realçou que as disposições da lei de anistia de 1979 são manifestamente incompatíveis com a Convenção Americana, carecem de efeitos jurídicos e não podem seguir representando um obstáculo para a investigação de graves violações de direitos humanos, nem para a identificação e punição dos responsáveis. Enfatizou a Corte que leis de anistia relativas a graves violações de direitos humanos são incompatíveis com o Di- 
reito Internacional e as obrigações jurídicas internacionais contraídas pelos Estados. Respaldou sua argumentação em vasta e sólida jurisprudência produzida por órgãos das Nações Unidas e pelo sistema interamericano, destacando também decisões judiciais emblemáticas, invalidando leis de anistia na Argentina, no Chile, no Peru, no Uruguai e na Colômbia. A conclusão é uma só: as leis de anistia violam o dever internacional do Estado de investigar e punir graves violações a direitos humanos.

Note-se que o relatório final da Comissão Nacional da Verdade endossa a relevância de conferir cumprimento à sentença da Corte Interamericana. Considero que a própria criação da Comissão Nacional da Verdade, mediante a Lei n. 12.528, em 18 de novembro de 2011, foi uma resposta do Brasil à comunidade internacional, realçando o impacto da sentença da Corte. Também, em 18 de novembro de 2011, foi adotada a lei que garante o acesso à informação, sob o lema de que a publicidade é a regra, sendo o sigilo a exceção. Com efeito, no regime democrático a regra é assegurar a disponibilidade das informações com base no princípio da máxima divulgação das informações; a exceção é o sigilo e o segredo. Observa-se o importante impacto da sentença da Corte na experiência brasileira. A decisão traduz a força catalisadora de avançar na garantia dos direitos à verdade e à justiça. De um lado, contribuiu para o fortalecimento da Comissão Nacional da Verdade, com a finalidade de resgatar as informações relativas ao período da repressão militar, em defesa do direito à memória coletiva. De outro lado, está a contribuir para o direito à justiça, combatendo a impunidade de graves violações de direitos humanos, que alimenta um continuísmo autoritário na arena democrática.

Direito à verdade e direito à informação simbolizam um avanço extraordinário ao fortalecimento do Estado de Direito, da democracia e dos direitos humanos no Brasil. São instrumentos capazes de transformar a dinâmica de poder dos atores sociais, revelando o sentido do presente e sua relação com o passado. Estes avanços da justiça de transição são reflexo do impacto da jurisprudência da Corte Interamericana na experiência brasileira.

\section{PPGD Unoesc/Editores da EJJL. Os PNDH's e a Secretaria de Direitos} Humanos da Presidência da República geraram os resultados esperados nesses últimos anos? Quais são nossos maiores desafios em termos de institucionalidade protetiva de direitos humanos?

O $3^{\circ}$ Programa Nacional de Direitos Humanos (PNDH3), adotado em 21 de dezembro de 2009, teve como mérito maior lançar a pauta de direitos humanos no debate público, como política de Estado, de ambiciosa vocação transversal.

Contempla 521 ações programáticas, alocadas em 6 eixos orientadores: interação democrática entre Estado e sociedade civil; desenvolvimento e direitos humanos; universalizar os direitos humanos em um contexto de desigualdades; segurança pública, acesso à justiça e combate à violência; educação e cultura em direitos humanos; e direito à memória e à verdade. O PNDH3 é fruto da $11^{\mathrm{a}}$ Conferência Nacional de 
Direitos Humanos, realizada em dezembro de 2008, a partir de um processo aberto e plural, contando com a participação da sociedade civil, de instituições, como também dos próprios atores governamentais, no exercício de um diálogo democrático marcado por "tensões, divergências e disputas", como reconhece o próprio prefácio ao PNDH3. Os diversos Ministérios foram convidados a participar do processo ao longo de quatro meses, contando o PNDH3 com a assinatura de todos os Ministros, tendo em vista a "transversalidade e a inter-ministerialidade de suas diretrizes." Espelha a própria dinâmica da historicidade dos direitos humanos, que, como lembra Norberto Bobbio, não nascem todos de uma vez e nem de uma vez por todas. Direito ao meio ambiente, direito ao desenvolvimento sustentável, direito à verdade, direitos dos idosos, direito à livre orientação sexual, direito aos avanços tecnológicos, entre outros, são temas que emergem na agenda contemporânea de direitos humanos. O Programa é reflexo das complexidades da realidade brasileira no campo dos direitos humanos, a conjugar uma pauta pré-republicana (por exemplo, o combate e prevenção ao trabalho escravo) com desafios da pós-modernidade (por exemplo, o fomento à implementação de tecnologias socialmente inclusivas e ambientalmente sustentáveis).

$\mathrm{O} 1^{\circ} \mathrm{PNDH}$ foi adotado na era FHC, em 1996, contendo metas na esfera dos direitos civis e políticos. Em 2002, adveio o $2^{\circ} \mathrm{PNDH}$, incluindo os direitos econômicos, sociais e culturais. O PNDH3 nasce com o objetivo de atualizar e ampliar o Programa anterior. A abrangência do Programa é reflexo da abrangência mesma que os direitos humanos assumem desde a Declaração Universal de 1948, a reunir em um só documento os direitos civis e políticos e os direitos econômicos, sociais e culturais, sob o prisma da universalidade e da indivisibilidade.

Uma das metas mais polêmicas do PNDH3 era a criação da Comissão Nacional de Verdade para examinar violações de direitos humanos praticadas no período da repressão política de 1964-1985 - tema já enfocado na resposta anterior. Creio que PNDH-3 contribuiu para avançar o processo de criação da Comissão, com todas as suas tensões e resistências.

Quanto ao controvertido tema do aborto, o PNDH3 endossa a aprovação de projeto de lei que descriminaliza o aborto, em respeito à autonomia das mulheres. A ordem internacional recomenda aos Estados que assumam o aborto ilegal como uma questão prioritária e que sejam revisadas as legislações punitivas em relação ao aborto, considerado um grave problema de saúde pública. $\mathrm{O}$ drama do aborto ilegal tem gerado um evitável e desnecessário desperdício de vidas de mulheres, acometendo com acentuada seletividade as mulheres que integram os grupos sociais mais vulneráveis.

A respeito das unióes homoafetivas, o PNDH3 expressa seu apoio à união civil entre pessoas do mesmo sexo, assegurando os direitos dela decorrentes, como a adoção. Aqui o PNDH-3 se antecipou à paradigmática decisão do STF de maio de 2011, reconhecendo proteção constitucional às uniões homoafetivas.

No que se refere à liberdade religiosa, o PNDH3 enuncia a meta de desenvolver mecanismos para impedir a ostentação de símbolos religiosos em estabelecimentos públicos. No Estado laico, marcado pela separação entre Estado e religião, 
todas as religiões merecem igual consideração e profundo respeito. A própria Constituição veda à União estabelecer cultos religiosos ou igrejas, subvencioná-los, embaraçar-lhes o funcionamento ou manter com eles ou seus representantes relações de dependência ou aliança. A ordem jurídica em um Estado Democrático de Direito deve manter-se laica e secular, não podendo se converter na voz exclusiva da moral de qualquer religião.

Se na época dos regimes ditatoriais a agenda dos direitos humanos era uma agenda contra o Estado, com a democratização os direitos humanos passam a ser também uma agenda do Estado - que combina a feição híbrida de agente promotor de direitos humanos e, por vezes, agente violador de direitos. Direitos humanos, democracia e Estado de Direito são termos interdependentes e inter-relacionados. Com o ímpeto de lançar as bases para a formulação de uma política nacional de direitos humanos, o PNDH3 prestou uma especial contribuição ao ampliar e intensificar o debate público sobre direitos humanos, acenando a ideia de que não há democracia, tampouco Estado de Direito, sem que os direitos humanos sejam respeitados.

Contudo, fundamental é avançar e fortalecer a institucionalidade afeta aos direitos humanos, assegurando dotação orçamentária adequada e absoluta prioridade. Fundamental, ainda, é garantir o enfoque transversal dos direitos humanos, a impactar as políticas públicas de todas as áreas, setores, Secretarias e Ministérios. Lamenta-se, aqui, a recente fusão de Secretarias Especiais, que estavam a prestar - cada qual ao seu modo - extraordinária contribuição à questão de gênero e diversidade étnica-racial.

6. PPGD Unibrasil/PPGD Unifor-CE/Editores da EJJL. O Brasil ainda tem práticas ou obstáculos jurídicos que poderiam ser classificados de graves violações ao direito humano à educação, à saúde, à renda básica e à igualdade de gênero? Em caso positivo, quais diretrizes de direitos humanos podem/devem ser operacionalizados para reverter situação?

$\mathrm{Na}$ resposta me concentrarei sobretudo no desafio da igualdade de gênero no caso brasileiro.

No mundo ocidental a construção dos direitos humanos das mulheres pode ser compreendida a partir de um marco divisório: pré e pós-década de 70. É justamente nas últimas 4 décadas que se concentram os maiores avanços da emancipação feminina. Jamais houve tantas conquistas civilizatórias em um lapso temporal historicamente tão curto.

Basta atentar que, até 1962, no Brasil, as mulheres casadas eram consideradas "relativamente incapazes" para os atos da vida civil. O Código Civil de 1916 (vigente até 2002) consagrava uma ótica sexista e patriarcal, que conferia ao homem a chefia da sociedade conjugal. Por sua vez, o Código Penal de 1940, contemplava diversos crimes que tinham como vítima a chamada "mulher honesta". 
Ao incorporar $90 \%$ das reivindicações do movimento de mulheres à época nos trabalhos constituintes, a Constituição de 1988 consolida um novo paradigma: igualitário, democrático e não sexista. Afirma a igualdade entre homens e mulheres em direitos e obrigações, enfatizando a igualdade entre os gêneros na esfera familiar. À luz do princípio da dignidade humana, prevê ser o planejamento familiar de livre decisão do casal, vedada qualquer coerção estatal. Estabelece o dever do Estado de coibir a violência no âmbito das relações familiares, dentre tantos outros avanços.

Passados mais de 25 anos da promulgação da Constituição, importantes desafios merecem ser enfrentados para assegurar o pleno exercício dos direitos humanos das mulheres no Brasil.

De acordo com o relatório “The Global Gender Gap - 2013”, lançado pelo World Economic Forum, o Brasil situa-se no $62^{\circ}$ lugar no ranking de desigualdade entre homens e mulheres em 136 países, tendo como indicadores o acesso à educação, à saúde, a participação econômica e política. O estudo conclui que nenhum país do mundo alcançou a plena igualdade entre homens e mulheres. Os países nórdicos revelam a menor desigualdade de gênero - despontando a Noruega, Suécia e Finlândia nos primeiros lugares do ranking -, enquanto os países árabes realçam os piores indicadores.

Se comparada com outros países latino-americanos, como a Argentina $\left(34^{\circ}\right.$ lugar) e a Colômbia ( $35^{\circ}$ lugar), preocupante mostra-se a performance brasileira, explicada, sobretudo, pela reduzida participação política de mulheres. Ainda que, no acesso à educação e à saúde, o Brasil apresente um dos melhores indicadores de nossa região, quanto à participação política atingimos a constrangedora $68^{\mathrm{a}}$ posição, muito distante da posição argentina $\left(34^{\mathrm{a}}\right)$, equatoriana $\left(17^{\mathrm{a}}\right)$ ou boliviana $\left(23^{\mathrm{a}}\right)$.

Ao longo da história atribuiu-se às mulheres a esfera privada - os cuidados com o marido, com os filhos e com os afazeres domésticos - enquanto aos homens foi confiada a esfera pública. Nas últimas décadas, no entanto, houve a crescente democratização do domínio público, com a significativa participação de mulheres, ainda remanescendo o desafio de democratizar o domínio privado - o que não somente permitiria o maior envolvimento de homens na vivência familiar com um grande ganho aos filhos(as), mas também a maior participação política de mulheres.

No mercado de trabalho, para as mesmas profissões e níveis educacionais, as mulheres brasileiras ganham cerca de $30 \%$ a menos do que os homens. Para José Pastore, "além das diferenças de renda, as mulheres enfrentam uma situação desfavorável na divisão das tarefas domésticas. Os maridos brasileiros dedicam, em média, apenas 0,7 hora de seu dia ao trabalho do lar. As mulheres que trabalham fora põem 4 horas diárias." Ainda, a taxa de desemprego na América Latina gira em torno de 7,2\% - contudo, de forma desagregada, está a alcançar 9,1\% das mulheres e $5,9 \%$ dos homens.

Se hoje há 1 bilhão de analfabetos adultos, 2/3 são mulheres. Consequentemente, $70 \%$ das pessoas que vivem na pobreza também o são - daí a feminização da pobreza. Garantir o empoderamento de mulheres é condição essencial para avançar 
no desenvolvimento. Os países com a menor desigualdade de gênero são justamente os mesmos que ostentam o maior índice de desenvolvimento humano.

Como lembra Amartya Sen, "nada atualmente é tão importante ao desenvolvimento quanto o reconhecimento adequado da participação e da liderança política, econômica e social das mulheres. Esse é um aspecto crucial do desenvolvimento como liberdade."

Adicione-se que, no âmbito global, a Organização Mundial de Saúde alerta ser pobreza a principal causa mortis do mundo - mata mais que todos os conflitos armados somados -, tendo sua influência destrutiva em cada estágio da vida humana, do momento do nascimento à morte.

No âmbito regional, a América Latina destaca-se como a região mais desigual do mundo, com 167 milhões vivendo na pobreza, sendo 71 milhões na pobreza extrema. Ainda que no período de 2002 a 2012 tenha ocorrido a redução da pobreza de 43,9\% a 28,1\% (e da pobreza extrema de 19,3\% a 11,3\%), em 2012 e 2013 houve a estagnação do processo de redução da pobreza na região (ver Economic Commission for Latin America and Caribbean - ECLAC, Social Panorama of Latin America, 2014). A região concentra 5 dos 10 países mais desiguais do mundo.

No âmbito nacional, enfrenta-se o desafio do aumento das desigualdades, do desemprego e da precarização do trabalho, que tem impacto desproporcional nas mulheres e nos povos afrodescendentes. Há a feminização e a etnização da pobreza.

Neste cenário, emergencial é propor medidas para o combate à pobreza. Os direitos sociais objetivam proteger as necessidades humanas básicas, assegurando condições materiais para uma vida com dignidade. Enuncia a Declaração Universal dos Direitos Humanos que toda pessoa, como membro da sociedade, tem direito à segurança social e à realização de direitos sociais indispensáveis à sua dignidade e ao livre desenvolvimento de sua personalidade (artigo 22). Direitos sociais demandam integração social, solidariedade e igualdade, com especial proteção aos mais vulneráveis. Não podem ficar condicionados à caridade, generosidade ou compaixão, mas devem ser respeitados como direitos.

Essencial é ampliar e fortalecer iniciativas e experiências locais para aliviar o sofrimento da pobreza. Como sustenta Philippe Van Parijs, professor das Universidades de Louvain e de Harvard, os grandes avanços da humanidade nos séculos XIX e XX foram, respectivamente, a abolição da escravidão e a adoção do sufrágio universal. No século XXI será o combate à pobreza, com instrumentos para promover a justiça social, radicada na dignidade, igualdade e liberdade real a todos.

\section{PPGD Unoesc/Editores da EJJL. É usual dizer que o desenvolvimento} humano só pode se realizar em contexto de crescimento econômico, ou seja, que sem crescimento econômico não pode haver avanços no desenvolvimento humano. A seu ver, o atual paradigma do desenvolvimento humano do PNUD representa uma nova forma de ver as relaçóes entre desenvolvimento humano e crescimento econômico? Isto é, podemos afirmar que é possível avançar na agenda do 
cumprimento e realização dos direitos humanos mesmo em contexto de crise? Ou, pelo contrário, primeiro teremos de encontrar a fórmula para retomar o crescimento do PIB e do controle das contas públicas?

Entendo que sim, é possível avançar na agenda do cumprimento e realização de direitos humanos mesmo em contexto de crise, a partir de uma concepção de desenvolvimento marcada pelo "human rights approach".

Tal concepção vem introduzida pela Declaração da ONU sobre o Direito ao Desenvolvimento, adotada em 1986, por 146 Estados, com um voto contrário (EUA) e 8 abstenções.

O direito ao desenvolvimento contempla, assim, três dimensões centrais:

a) Justiça social

De acordo com o artigo 28 da Declaração de Direitos Humanos: "Toda pessoa tem direito a uma ordem social e internacional em que os direitos e liberdades estabelecidos na Declaração possam ser plenamente realizados."

A justiça social é um componente central à concepção do direito ao desenvolvimento. A realização do direito ao desenvolvimento, inspirado no valor da solidariedade, há de prover igual oportunidade a todos no acesso a recursos básicos, educação, saúde, alimentação, moradia, trabalho e distribuição de renda.

Para a Declaração sobre o Direito ao Desenvolvimento, o desenvolvimento compreende um processo econômico, social, cultural e político, com o objetivo de assegurar a constante melhoria do bem-estar da população e dos indivíduos, com base em sua ativa, livre e significativa participação neste processo, orientada pela justa distribuição dos benefícios dele resultantes. Reconhece o artigo $2^{\circ}$ da Declaração que: "A pessoa humana é o sujeito central do desenvolvimento e deve ser ativa participante e beneficiária do direito ao desenvolvimento."

$\mathrm{Na}$ promoção do desenvolvimento, igual consideração deve ser conferida à implementação, promoção e proteção dos direitos civis, políticos, econômicos, sociais e culturais. Medidas efetivas devem ser ainda adotadas a fim de proporcionar às mulheres um papel ativo no processo de desenvolvimento.

\section{b) Participação e accountability}

Além do componente de justiça social, o componente democrático é essencial ao direito ao desenvolvimento.

É dever dos Estados encorajar a participação popular em todas as esferas como um importante fator ao direito ao desenvolvimento e à plena realização dos direitos humanos. Estados devem promover e assegurar a livre, significativa e ativa participação de indivíduos e grupos na elaboração, implementação e monitoramento de políticas de desenvolvimento.

Para Amartya Sen, os direitos políticos (incluindo a liberdade de expressão e de discussão) são não apenas fundamentais para demandar respostas políticas às necessidades econômicas, mas são centrais para a própria formulação destas neces- 
sidades econômicas ${ }^{6}$. Daí a relação indissociável entre o exercício dos direitos civis e políticos e o exercício dos direitos sociais, econômicos e culturais.

Neste contexto, os princípios da participação e da accountability são centrais ao direito ao desenvolvimento.

c) Programas e políticas nacionais e cooperação internacional

O direito ao desenvolvimento compreende tanto uma dimensão nacional, quanto uma dimensão internacional.

Prevê a Declaração sobre o Direito ao Desenvolvimento que os Estados devem adotar medidas - individual e coletivamente - para criar um ambiente a permitir, nos planos internacional e nacional, a plena realização do direito ao desenvolvimento. Ressalta a Declaração que os Estados devem adotar medidas para eliminar os obstáculos ao desenvolvimento resultantes da não observância de direitos civis e políticos, bem como da afronta a direitos econômicos, sociais e culturais. Ainda que a Declaração reconheça ser os Estados os responsáveis primários na realização do direito ao desenvolvimento, enfatiza a importância da cooperação internacional para a realização do direito ao desenvolvimento.

Adiciona o artigo $4^{\circ}$ da Declaração que os Estados têm o dever de adotar medidas, individual ou coletivamente, voltadas a formular políticas de desenvolvimento internacional, com vistas a facilitar a plena realização de direitos, acrescentando que a efetiva cooperação internacional é essencial para prover aos países em desenvolvimento meios que encorajem o direito ao desenvolvimento.

O direito ao desenvolvimento demanda uma globalização ética e solidária.

Desse modo, um dos mais extraordinários avanços da Declaração de 1986 é lançar o human rights-based approach ao direito ao desenvolvimento. O human rights-based approach é uma concepção estrutural ao processo de desenvolvimento, amparada normativamente nos parâmetros internacionais de direitos humanos e diretamente voltada à promoção e à proteção dos direitos humanos. O human rights-based approach ambiciona integrar normas, standards e princípios do sistema internacional de direitos humanos nos planos, políticas e processos relativos ao desenvolvimento. A perspectiva de direitos endossa o componente da justiça social, realçando a proteção dos direitos dos grupos mais vulneráveis e excluídos como um aspecto central do direito ao desenvolvimento.

No dizer de Mary Robinson: "The great merit of the human rights approach is that it draws attention to discrimination and exclusion. It permits policy makers and observers to identify those who do not benefit from development. [...] so many development programmes have caused misery and impoverishment - planners only

${ }_{6}^{6}$ Ver SEN, Amartya. Prefácio do livro Pathologies of Power. Paul Farmer. Berkeley: University of California Press, 2003. 
looked for macro-scale outcomes and did not consider the consequences for particular communities or groups of people."

O desenvolvimento há de ser concebido como um processo de expansão das liberdades reais que as pessoas podem usufruir para adotar a concepção de Amartya Sen $^{8}$. A Declaração de Viena de 1993 enfatiza ser o direito ao desenvolvimento um direito universal e inalienável, parte integral dos direitos humanos fundamentais, reconhecendo a relação de interdependência entre a democracia, o desenvolvimento e os direitos humanos.

8. PPGD Unoesc/Editores da EJJL. O modo como se pesquisam direitos humanos no Brasil segue as melhores práticas da comunidade científica mundial? Há pesquisas realizadas no Brasil sobre DDHH que já podem ser consideradas de referência internacional? $O$ que a pós-graduação em direito do Brasil ainda precisa fazer para que a cultura dos direitos humanos se estabeleça definitivamente?

Enuncia o artigo 26 da Declaração Universal dos Direitos Humanos que toda pessoa tem direito à educação e que a educação será orientada no sentido do pleno desenvolvimento da personalidade humana e do fortalecimento e do respeito dos direitos humanos e das liberdades fundamentais. No mesmo sentido, o artigo 13 do Pacto Internacional dos Direitos Econômicos, Sociais e Culturais estabelece que a educação deverá visar ao pleno desenvolvimento da personalidade humana e do sentido de sua dignidade e a fortalecer o respeito pelos direitos humanos e pelas liberdades fundamentais. Consolida-se, assim, o direito à educação em direitos humanos como um direito humano fundamental.

Acrescenta a Unesco que o processo educacional deve ser orientado pela incorporação de valores, atitudes e habilidades voltadas ao pleno desenvolvimento da personalidade humana.

Sustento que 4 são os fatores que permitem compor o diagnóstico da educação em direitos humanos no Brasil:

1) o processo de democratização política;

2) a relação entre democracia e direitos humanos;

\footnotetext{
7 Extraído de: ROBINSON, Mary. What Rights can add to good development practice. In: ALSTON, Philip; ROBINSON, Mary (Ed.). Human Rights and Development: towards mutual reinforcement. Oxford: Oxford University Press, 2005. p. 36.

8 Ao conceber o desenvolvimento como liberdade, sustenta Amartya Sen: "Neste sentido, a expansão das liberdades é vista concomitantemente como 1) uma finalidade em si mesma e 2) o principal significado do desenvolvimento. Tais finalidades podem ser chamadas, respectivamente, como a função constitutiva e a função instrumental da liberdade em relação ao desenvolvimento. A função constitutiva da liberdade relaciona-se com a importância da liberdade substantiva para o engrandecimento da vida humana. As liberdades substantivas incluem as capacidades elementares, como a de evitar privações como a fome, a sub-nutrição, a mortalidade evitável, a mortalidade prematura, bem como as liberdades associadas com a educação, a participação política, a proibição da censura. Nesta perspectiva constitutiva, o desenvolvimento envolve a expansão destas e de outras liberdades fundamentais. Desenvolvimento, nesta visão, é o processo de expansão das liberdades humanas." (SEN, 2003, p. 35-36, 297). Sobre o direito ao desenvolvimento, ver também VASAK, Karel. For Third Generation of Human Rights: The Rights of Solidarity. International Institute of Human Rights, 1979.
} 
3) a reconstrução do marco normativo (mediante a adoção da Constituição de 1988, inspiradora de toda uma legislação nacional protetiva de direitos humanos, bem como impulsionadora da ratificação de tratados internacionais de proteção dos direitos humanos); e

4) a crescente incorporação da pauta dos direitos humanos na redefinição das agendas institucionais no contexto da democratização.

É este o contexto que propiciou às Universidades a reavaliação de seu papel e de sua responsabilidade na construção de uma cultura de proteção aos direitos humanos.

$\mathrm{Na}$ esfera universitária, emergiram, paulatinamente, nos programas de Graduação e Pós-Graduação do país, iniciativas e experiências inéditas voltadas à inserção dos direitos humanos no ensino superior. O levantamento das experiências nacionais voltadas aos Direitos Humanos no ensino superior reflete a pluralidade de respostas de Universidades, que incorporaram, cada qual ao seu modo, os direitos humanos como pauta institucional, a partir de suas peculiaridades e especificidades.

Em relação aos cursos jurídicos, importa realçar que a sua criação no Brasil - no início do século XIX - confunde-se com a história de formação do Estado Nação. Isto é, as escolas de Direito de Olinda e São Paulo tiveram como objetivo maior formar e qualificar o quadro dirigente do país, no marco da "República dos Bacharéis".

Em 2016, outra é a vertente, identidade, propósito e vocação dos cursos jurídicos. Contudo, cabe enfatizar que ao menos um dos Poderes da República - o poder Judiciário - é integralmente composto por aqueles(as) com formação jurídica.

É a partir deste cenário que são lançadas cinco propostas e estratégias para avançar no ensino jurídico visando à construção de uma cultura de direitos humanos no país:

1) Fortalecer a adoção de um novo paradigma jurídico (o que está a demandar um profundo câmbio cultural, como já enfocado na resposta à primeira questão);

2) Fomentar uma cultura jurídica orientada pelo controle da convencionalidade das leis;

3) Difundir amplamente a normatividade interna e internacional voltada à proteção dos direitos humanos;

4) Fomentar programas de capacitação para que os agentes jurídicos apliquem os parâmetros protetivos internacionais;

5) Fortalecer os direitos humanos no ensino jurídico mediante o ensino, a pesquisa e a extensão.

No campo do ensino, fundamental é não apenas a criação de disciplinas específicas na Graduação e na Pós, programas específicos e cursos de especialização e extensão universitária, mas ainda captar a transversalidade dos direitos humanos - que devem guiar o ensino de todas as disciplinas do curso jurídico, com base nos 
parâmetros constitucionais e internacionais emancipatórios, voltados à prevalência da dignidade humana, por meio de uma metodologia aberta e baseada no diálogo.

No campo da pesquisa - considerando que as Universidades surgem como privilegiado locus de produção do saber - os cursos jurídicos devem estimular pesquisas e investigações no campo dos direitos humanos, à luz de temas de especial prioridade nacional (ex. proteção aos direitos sociais; combate à discriminação; proteção aos grupos mais vulneráveis; combate à violência e à impunidade, dentre outros).

No que se refere à extensão, na dimensão extra muros da Universidade que dialoga e interage com a comunidade - fundamental é criar clínicas de direitos humanos, com progamas de advocacy, proteção, promoção e capacitação em direitos humanos.

Por fim e tendo em vista o papel vital do ensino jurídico no campo dos direitos humanos, seja por meio do ensino (transmissão do saber), da pesquisa (produção do saber) e da extensão (intervenção social), há que se resgatar o potencial ético e transformador das Universidades, na construção de uma cultura de direitos humanos em nosso país, já que os direitos humanos refletem a única plataforma emancipatória de nosso tempo.

Data da submissão: 22 de dezembro de 2015 Aceito em: 27 de janeiro de 2016 
